\title{
O Brasil na hora de ler Maquiavel: notas sobre a primeira edição brasileira d'O príncipe, traduzido por Elias Davidovich
}

\author{
Sandra Bagno[1]
}

\begin{abstract}
Resumo
O estudo da recepção das obras e ideias de Maquiavel no Brasil revela que, somente na década de 1930, foi publicado, pela primeira vez no âmbito da lusofonia, O príncipe. No entanto, desde o Quinhentos, na Europa, e apesar de sua inserção em 1559 no Index dos livros proibidos, a obra vinha sendo publicada e circulava de várias maneiras. Longe de aproveitar-se da possibilidade de fazer jus - depois de quase quatro séculos - ao fundador da ciência política moderna, a tradução de 1933, proposta pela editora carioca Calvino Filho, é apresentada por um prefácio de Mauricio de Medeiros. Mesmo engajado na luta para a liberdade e contra o autoritarismo de Getúlio Vargas, seu prefácio, analisado pelo viés paratextual, revela-se destinado a reafirmar, ainda no século XX, a tradicional interpretação da obra maquiaveliana, imposta, a partir dos níveis linguístico e lexicográfico, pelos (não propriamente libertários) inquisidores portugueses.
\end{abstract}

Palavras-chave: Maquiavel; O príncipe; tradução brasileira.

Brasil al leer a Maquiavelo: notas acerca de la primera edición brasileña de El príncipe, traducido por Elias Davidovich

\section{Resumen}

El estudio de la respuesta a las obras y las ideas de Maquiavelo en Brasil revela que apenas en la década de 1930 se publicó El príncipe por primera vez en el ámbito de la lusofonia. Sin embargo, desde el siglo XVI, en Europa, y aunque fue incluida en 1559 en el Index de los libros prohibidos, la obra se había publicado y circulaba de muchas maneras. Lejos de aprovechar la oportunidad de hacer justicia - tras casi cuatro siglos al fundador de la ciencia política moderna, la traducción de 1933, publicada por la editorial Calvino Filho, de Rio de Janeiro, es introducida por un prólogo de Mauricio de Medeiros. Aunque está involucrado en la lucha por la libertad y contra el autoritarismo de Getúlio Vargas, su prefacio, analizado por la perspectiva paratextual, revela la intención de reafirmar, incluso en el siglo XX, la interpretación tradicional de la obra maquiaveliana que se impuso desde los niveles lingüístico y lexicográfico por los (no exactamente libertarios) inquisidores portugueses.

Palabras clave: Maquiavelo; El príncipe; traducción brasileña.

\section{Brazil when reading Machiavelli: notes on the first Brazilian edition of The Prince, translated by Elias Davidovich}

\section{Abstract}

The study of the Brazilian response to Machiavellis books and ideas reveals that The Prince was published for the first time only in the 1930s in the Portuguese-speaking countries. Nevertheless, since the $16^{\text {th }}$ century in Europe, and despite the fact that it had been listed in 1559 in the Index of prohibited books, the work was being published and circulated in several ways. Far from taking advantage of the possibility of doing justice, almost four centuries later, to the founder of the modern political science, the translation of 1933, published by the Calvino Filho publishing house, in Rio de Janeiro, is introduced by a preface written by Mauricio Medeiros. Although politically engaged in the fight for freedom and against the authoritarianism of Getúlio Vargas, his preface, if analyzed from a paratextual perspective, seems meant to reaffirm, in the $20^{\text {th }}$ century, the traditional interpretation of the Machiavellian work done by the (not strictly libertarian) Portuguese inquisitors at linguistic and lexicographic levels.

Keywords: Machiavelli; The Prince; Brazilian translation.

\section{Brésil au moment de lire Machiavel: notes sur la première édition brésilienne de Le prince, traduit par Elias Davidovich}

Résumé

Lorsque l'on examine la réception des ouvrages et des idées de Machiavel au Brésil, on remarque que Le prince n`a été publié que dans les années 1930 dans la domaine de la lusophonie. Toutefois, depuis Le Cinq Cents, en Europe, et malgré sa insertion à l'index d'ouvrages interdits dans 1559, le texte était publié et circulait de nombreuses manières. La traduction de 1933, proposée par la maison d'édition Calvino Filho sans faire honneur, après près de quatre siècles, au fondateur de la science politique moderne - a été présentée avec la préface de Mauricio de Medeiros. Même engagée dans le combat pour la liberté et contre l'autoritarisme de Getúlio Vargas, la préface, en se fondant sur biais para-textuel, vise à réaffirmer l'interprétation traditionnelle de l'œuvre de Machiavel même au XXème siècle; une interprétation imposée par inquisiteurs portugais - pas exactement libertariens - partant des niveaux linguistique et lexicographique.

Mots clés: Machiavel; Le prince; traduction brésilienne. 


\section{A questão Maquiavel}

$\mathrm{M}$ uitos são os eventos que, no momento, celebram em âmbito internacional o quinto centenário da composição original de um clássico, ${ }^{1}$ O príncipe, do florentino Nicolau Maquiavel, cuja obra foi totalmente incluída durante o Quinhentos, como se sabe, no Index librorum prohibitorum, tanto o romano como o português. ${ }^{2}$ Porém, estudos cada vez mais abrangentes demonstram que, mesmo proibida e estigmatizada por longo tempo, a obra maquiaveliana começou logo a ser traduzida e publicada, circulando, assim, de várias formas na Europa. ${ }^{3}$

Quando, então, O príncipe teria começado a circular no Brasil e de quais maneiras? Quando foi integralmente traduzido e publicado pela primeira vez em português? Em função dessas pesquisas internacionais que permitem reconstruir mediante o exame de muitas e variadas realidades europeias - um mapa cada vez mais complexo dos diferentes maquiavelismos, ${ }^{4}$ há elementos para tratar da existência de um "maquiavelismo" especificamente "brasileiro"? Por fim, seria possível detectar até quando o Brasil manter-se-ia, em sua inteligência mais representativa, nos rastros de uma interpretação tradicional, proveniente da herança inquisitorial portuguesa quanto à chamada "questione del Machiavelli" segundo a célebre expressão de Benedetto Croce? ${ }^{5}$ Essa questão foi exposta pelo filósofo italiano em 1949 nos seguintes termos:

Ho avuto occasione di leggere in questi ultimi anni parecchi libri, italiani e stranieri sul Machiavelli; e, ricercando l'intima ragione dello scontento, che mi avevano lasciato, l'ho ritrovata, come in altri casi simili o analoghi, nella deficienza o nell'insufficienza di logica speculativa con cui vi era stato trattato il relativo problema, o «questione del Machiavelli», la quale non è, come si crede, una questione di morale, ma di filosofia della morale, e, come di natura filososfica, richiede quella logica. ${ }^{6}$

Ora, não é fácil entender se, entre os "muitos livros, italianos e estrangeiros" a que alude Croce ao escrever sobre a "insuficiência de lógica especulativa" no trato da "questão do Maquiavel", haveria também algum material em português, ou ligado de certo modo às culturas lusófonas. Sabemos, porém, que um

\footnotetext{
'Federico Chabod, "La genesi del 'Principe' ", In: Scritti su Machiavelli, Torino, Einaudi, 1964, p. 34. ${ }^{2}$ Rodolfo De Mattei, Dal premachiavellismo all'antimachiavellismo, Firenze, Sansoni, 1969, p. 223 et seq. ${ }^{3} \mathrm{Cf}$. Rodrigo Bentes Monteiro; Sandra Bagno (orgs.), Maquiavel no Brasil. Dos descobrimentos ao século XXI. Rio de Janeiro, Editora FGV; Faperj, no prelo.

4Para uma bibliografia essencial e atualizada sobre Maquiavel e os maquiavelismos, Alessandro Campi (org.) Il principe di Niccolò Machiavelli e il suo tempo 1513-2013, Roma, Istituto della Enciclopedia Italiana fondata da Giovanni Treccani, 2013.

${ }^{5}$ Cf. Rodrigo Bentes Monteiro; Sandra Bagno, op cit. "Questão do Maquiavel” (tradução da autora).

6"Tive a oportunidade de ler nestes últimos anos muitos livros, italianos e estrangeiros, sobre Maquiavel: e, procurando a razão profunda do descontentamento em que me deixaram, encontrei-a, como em outros casos similares ou análogos, na deficiência ou insuficiência de lógica especulativa com que neles tinha sido tratado o relativo problema, ou 'questão do Maquiavel', a qual não é, como acredita-se, uma questão de moral, mas sim de filosofia da moral, e, sendo de natureza filosófica, impõe aquela lógica" (tradução da autora) Benedetto Croce, "Una questione che forse non si chiuderà mai. La questione del Machiavelli", Quaderni della "Critica", n. 14, Jul. 1949, p. 1. Disponível em: <http://ojs.uniroma1.it//index.php/quadernidellacritica/article/ view/1938/1935>. Acesso em: 12 de julho de 2013.
} 
dos primeiros e mais radicais detratores da obra maquiaveliana foi, no Quinhentos português, o bispo Jerónimo Osório, ${ }^{7}$ e que a interpretação de matriz inquisitorial da obra do secretário florentino ficaria arraigada na lusofonia - conforme depreende-se do exame dos dicionários de português permanecendo inalterada até o século XX. ${ }^{8}$ Sendo a abordagem linguística semântico-lexical imprescindível para reconstruir um possível perfil do maquiavelismo no Brasil, realizamos alguns estudos sobre as definições das palavras derivadas do substantivo "Maquiavel" registradas pelos dicionários ao longo dos séculos. Mesmo sendo atestada há décadas no português brasileiro a palavra "maquiaveliano", usada com sentidos claramente denotativos, ou seja, isentos de preconceitos, ela quase não aparece nos dicionários. Portanto, ainda hoje continuam registrados, em geral, somente verbetes com significados depreciativos. ${ }^{9}$ Quais seriam as consequências, então, advindas desse condicionamento semântico-lexical, principalmente em prefácios e comentários das traduções brasileiras d'O príncipe?

Antes de procurarmos responder a essas perguntas, atentemos aos motivos pelos quais Croce fala numa "razão profunda" de "descontentamento" ao ler "muitos livros, italianos e estrangeiros" sobre Maquiavel. Afirma o filósofo italiano:

So bene che al Machiavelli è stata negata la qualità di filosofo $\mathrm{e}$ si è sorriso di coloro che vogliono farlo filosoficamente parlare, e la sua importanza è stata riposta in altre cose, tra le quali c'è una che si suole ancora ripetere ma che confesso di non intendre; cioè, che egli non fece altro che mettere in iscritto quello che era il costume dell'età sua. Un amanuense o un echeggiatore mi pare che non solo non sia un pensatore, ma neppure uno scrittore che, per essere interprete di una età, deve esserne il critico, cioè intenderla e discernerla e qualificarla. ${ }^{10}$

Mas Croce localizou mais duas linhas interpretativas da obra maquiaveliana, a seu ver, incorretas:

\footnotetext{
${ }^{7}$ Giuseppe Marcocci, A consciência de um império. Portugal e o seu mundo (sécs. XV-XVIII), Coimbra, Imprensa da Universidade de Coimbra, 2012, p. 251 et seq. Manuel Augusto Rodrigues, A obra exegética de D. Jerónimo Osório no contexto do Humanismo, da Reforma e da Contra-Reforma, Separata da revista Theologica, vol. XVI, fsc. III-IV, Braga, 1983.

${ }^{\circledR}$ Sandra Bagno, "/l principe di Machiavelli nelle lessicografie latinoamericane: il Brasile caso emblematico? Dall'eredità culturale del colonizzatore all'autonomia lessicografica specchio di un'identità nazionale", In: María Begoña Arbulu Barturen; Sandra Bagno, La recepción de Maquiavel y Beccaria en ámbito ibero-americano, Padova, Unipress, 2006, p. 183-240.

9/dem, '“Maquiavélico' versus 'maquiaveliano' na língua e nos dicionários monolíngues brasileiros", Cadernos de tradução, vol. 2, n. 22, Florianópolis, 2008, p. 129-150. Disponível em: <http://www.periodicos.ufsc.br/index. php/traducao/article/view/2175-7968.2008v2n22p129>. Acesso em: 29 de setembro de 2013.

10"Sei bem que foi negada a Maquiavel a qualidade de filósofo e que ele sorriu-se daqueles que querem fazê-lo filosoficamente falar, e que sua importância foi atribuída a outras coisas, dentre elas uma que ainda costuma repetir-se, mas que confesso não entender; ou seja, que ele não teria feito nada mais que colocar por escrito os costumes do seu tempo. Um amanuense ou um divulgador, parece-me que não seja somente um pensador, mas nem um escritor que, por ser intérprete de uma época, deve exercer sobre ela uma ação crítica, quer dizer, entendê-la, analisá-la e qualificá-la" (tradução da autora). Benedetto Croce, "Una questione che forse non si chiuderà mai. La questione del Machiavelli", Quaderni della "Critica", n. 14, Jul. 1949, p. 1. Disponível em: <http://ojs.uniroma1.it/index.php/quadernidellacritica/article/view/1938/1935>. Acesso em: 12 de julho de 2013
} 
Un'altra interpretazione del Machiavelli, che il Foscolo nei Sepolcri mise in bellissimi versi e che già era stata escogitata da Benedetto Spinoza, ne faceva uno svelatore ai popoli delle oppressioni e crudeltà dei sovrani assoluti: alla qual cosa il Machiavelli non pensò mai. Una terza lo considera ardente patriota italiano, che sulla salvezza e grandezza della patria raccolse tutti gli sforzi della sua mente e tutta la passione del suo cuore; e questo è vero, ma in questo egli ebbe molti e nobilissimi suoi pari, laddove nell'atteggiamento mentale che fu veramente suo, fu il solo o primo, sicchè ebbe molti consapevoli o inconsapevoli scolari anche fra quelli che lo rinnegavano o credevano di rinnegarlo. ${ }^{11}$

Portanto, seriam erradas, segundo Croce, mesmo encontradas em muitos livros, as teses pelas quais Maquiavel "não teria feito nada mais que colocar por escrito os costumes do seu tempo". Outra acepção seria a de "um revelador aos povos das opressões e crueldades dos monarcas absolutos". Ou, então, apenas "um férvido patriota italiano que empenhou todas as energias de sua mente e toda a paixão do seu coração para a grandeza e a salvação da pátria". Tomando como referência o esquema analítico do filósofo italiano, seriam registradas também no Brasil interpretações da obra maquiaveliana - cronologicamente anteriores a 1949 — baseadas em um ou mais desses três conceitos, segundo Croce incorretos?

\section{A primeira tradução para o português}

Estudos realizados em Portugal e no Brasil permitem-nos responder à segunda pergunta. Ao comparar o ambiente lusófono a outros grandes meios linguísticos e culturais de matriz europeia, deve-se reconhecer, em primeiro lugar, o "atraso" com que Il principe foi publicado integralmente traduzido para o português e começou a circular livremente no país. ${ }^{12}$ Contrariamente ao ocorrido em contextos linguísticos como o inglês, o espanhol, o francês etc. ${ }^{13}$ apenas nos anos 30 do Novecentos foi publicada no Rio de Janeiro a primeira tradução, em cuja capa

\footnotetext{
11“Uma outra interpretação de Maquiavel, que Foscolo em Os sepulcros colocou em versos belíssimos e que já tinha sido proposta por Bento Espinoza, fazia de Maquiavel um revelador aos povos das opressões e crueldades dos monarcas absolutos: coisa que Maquiavel nunca pensou. Uma terceira, considera-o um férvido patriota italiano que empenhou todas as energias da sua mente e toda a paixão de seu coração para a grandeza e a salvação da pátria; e isso é verdade, mas nisso ele teve muitos e nobilíssimos pares, enquanto na atitude mental verdadeiramente dele, Maquiavel foi o único e o primeiro; de tal forma que ele teve muitos discípulos conscientes ou inconscientes, também entre aqueles que o renegavam ou acreditavam renegá-lo" (tradução da autora). Benedetto Croce, "Una questione che forse non si chiuderà mai. La questione del Machiavelli", Quaderni della "Critica", n. 14, Jul. 1949, p. 1. Disponível em: <http://ojs.uniroma1.it/index.php/quadernidellacritica/article/ view/1938/1935>. Acesso em: 12 de julho de 2013.

${ }^{12}$ Sandra Bagno, "Il principe nell'area luso-brasiliana e le sue prime traduzioni in portoghese", In: Alessandro Campi (ed.), Il principe di Niccolò Machiavelli e il suo tempo 1513-2013, Roma, Istituto della Enciclopedia Italiana fondata da Giovanni Treccani, 2013, p. 219-220.

${ }^{13}$ Nella Bianchi Bensimon, "Il principe di Machiavelli nella Francia del XVI secolo"; Jacob Soll, "La traduzione del Principe di Amelot (1683)"; Maurizio Tarantino, "Il principe nella tradizione politico-letteraria europea dell'Ottocento", In: Alessandro Campi, op cit., p. 177-183; 184-185; 259-268.
} 
lê-se textualmente: "Nicholas Machiavel. O principe. Tradução de Elias Davidovich Prefacio de Mauricio de Medeiros, 1933, Calvino Filho Editor" (Figura 1). ${ }^{14}$

Dois anos depois, em 1935, seria publicada em Coimbra a primeira tradução integral portuguesa. ${ }^{15}$ Vale, no entanto, ressaltar um dado importante, concernente a uma das questões colocadas, sobre a recepção das obras de Maquiavel e o maquiavelismo no âmbito linguístico e cultural lusófono. Mesmo sendo a área luso-brasileira uma das mais atrasadas em relação à tradução e à publicação do Il principe, isso não significa que, nesse contexto, as obras maquiavelianas tenham permanecido desconhecidas. Giuseppe Marcocci afirma ser possível reconhecer claros indícios de conceitos maquiavelianos, camuflados com sabedoria, na tratadística política portuguesa pouco posterior às primeiras edições romanas dos Discorsi sopra la prima Deca di Tito Livio (1531) e do De principatibus (1532). ${ }^{16}$ A força inovadora das ideias maquiavelianas seria logo percebida. Se, por um lado, houve uma imediata adoção, pelos letrados portugueses, dos ensinamentos do secretário florentino - levando Portugal, segundo as palavras de Marcocci, a fortalecer o seu império “à sombra de Maquiavel" —, ${ }^{17}$ por outro, viriam do mesmo contexto lusitano duas reações de significado inequívoco ao já acenado: a tomada de posição de Jerónimo Osório e a condenação das obras de Maquiavel no Index librorum prohibitorum.

\section{Estudos sobre as definições das palauras derivadas \\ do substantivo "Maquiavel" nos dicionários ao \\ longo dos séculos demonstram que ainda hoje \\ continuam registrados, em geral, somente \\ verbetes com significados depreciativos}

Essas condenações produziram uma situação paradoxal: teoricamente, ninguém poderia ler, por serem proibidas, as obras de Maquiavel. Mas, ao mesmo tempo, o nome do secretário florentino fixar-se-ia na língua portuguesa também como um nome comum, a ponto de ser rotulado como substantivo nos dicionários, como vimos, apenas com acepções conotativas depreciativas. Se o Vocabulario portuguez \& latino de Rafael Bluteau registra, em 1727, os verbetes "Machiavel" e "Machiabelista",18 a família de palavras derivada de

\footnotetext{
${ }^{14}$ Quando não referidas de outro modo, as citações, incluindo os nomes próprios, serão sempre correspondentes aos textos-fonte e suas ortografias.

${ }^{15}$ Nicolau Maquiavel, O príncipe. Com um artigo de Mussolini a servir de introdução, Tradução de Francisco Morais, Coimbra, Atlântida; Livraria Editora Coimbra, 1935.

${ }^{16}$ Giuseppe Marcocci, A consciência de um império. Portugal e o seu mundo (sécs. XV-XVIII), Coimbra, Imprensa da Universidade de Coimbra, 2012, p. 251 et seq.

17/dem, "Construindo um império à sombra de Maquiavel", In: Bentes Monteiro; Sandra Bagno (orgs.), Maquiavel no Brasil. Dos descobrimentos ao século XXI. Rio de Janeiro, Editora FGV; Faperj, no prelo.

${ }^{18}$ Raphael Bluteau, Vocabulario portuguez \& latino, vol. 5, Coimbra, Collegio das Artes da Companhia de Jesu, 1712-1727. T. V (L.M.N.), p. 234. Disponível em: <http://www.brasiliana.usp.br/en/dicionario/1/machiabelista>. Acesso em: 29 de setembro de 2013.
} 


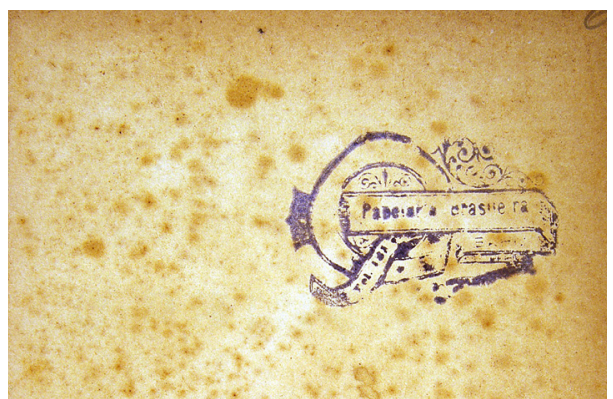

O PRINCIPE
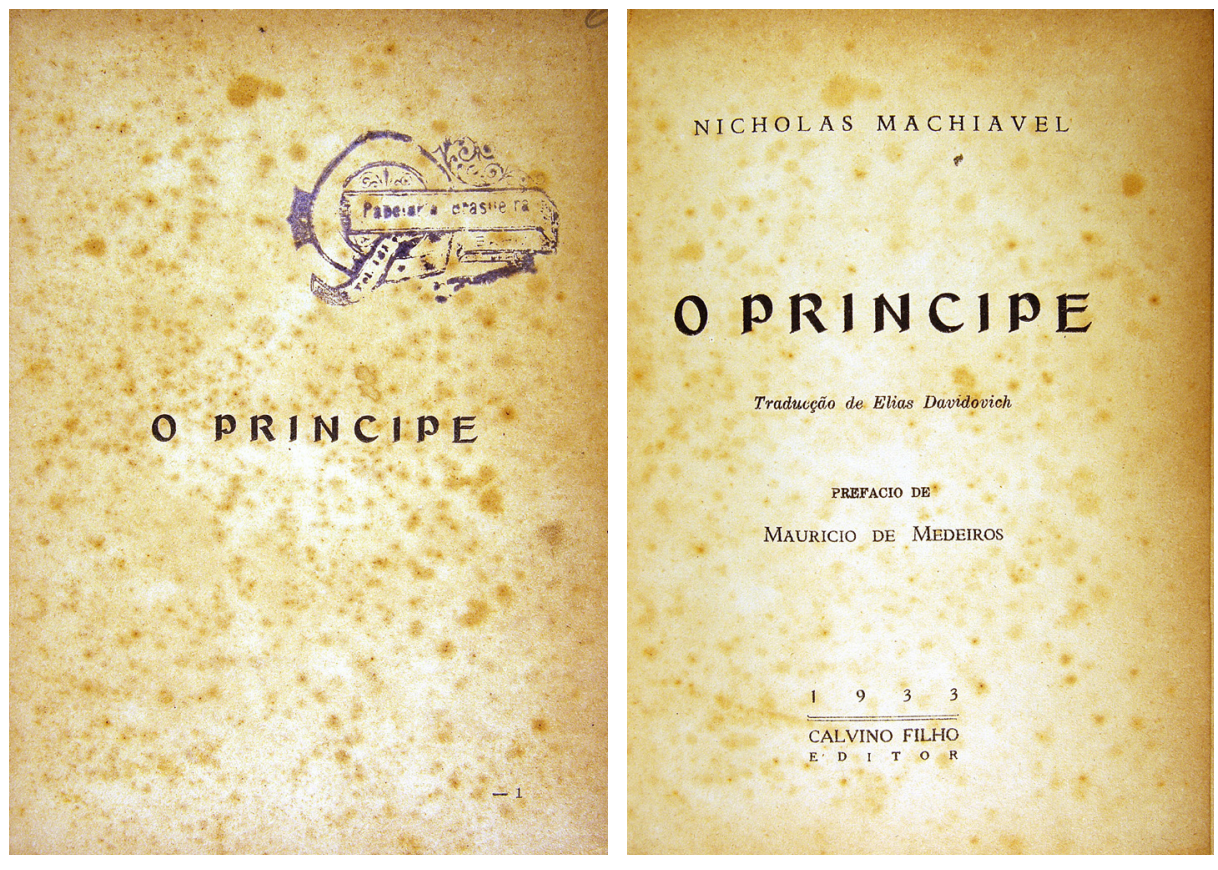

Figura 1. Fotografias das contracapas de Nicholas Machiavel, O principe. Tradução de Elias Davidovich, prefácio de Mauricio de Medeiros, Rio de Janeiro, Calvino Filho, 1933.

"Machiavel" aumentaria ao longo dos séculos. Nos séculos XIX e XX, obras autorizadas como o Novo diccionário da língua portuguesa (1926), de Candido de Figueiredo, ${ }^{19}$ e o Grande dicionário da língua portuguesa (1954), de António de Morais Silva, ${ }^{20}$ registrariam, respectivamente, seis e sete verbetes com acepções conotativas depreciativas. Portanto, a tradução brasileira e a portuguesa foram publicadas após o início de um processo de releitura, em âmbito internacional, das obras do secretário florentino. Ambas seriam, assim, anteriores às reflexões de Croce e, portanto, suscetíveis de serem consideradas segundo o seu esquema analítico, proposto cerca de 15 anos depois pelo filósofo italiano.

Seria então possível reconhecer na primeira edição - a brasileira, de Calvino Filho - uma forma de tomada de consciência da distorção produzida sobre a obra de Maquiavel, pela censura portuguesa, de certo modo refletida em nível linguístico pelos lexicógrafos? Ou seja, como viver-se-ia no Brasil, que há pouco mais de uma década celebrara o centenário da própria independência, uma oportunidade de perfurar o véu da herança inquisitorial sobre uma questão tão emblemática, relativa à sua plurissecular exclusão - conforme Wilson Martins $^{21}$ - das conquistas culturais do Rinascimento italiano? Essa ocasião dar-se-ia sob o signo de novas interpretações da obra maquiaveliana, feitas na Europa iluminista e/ou romântica? Ou a tradução de Calvino Filho confirmaria,

\footnotetext{
${ }^{19}$ Candido de Figueiredo, Novo diccionário da língua portuguesa, vol. II, Portugal; Brasil, Arthur Brandão, 1926, p. 92. ${ }^{20}$ António de Morais Silva, Grande dicionário da língua portuguesa, vol. VI (IRI-MOR), Lisboa, Confluência, 1954, p. 500. Trata-se de edição revista e ampliada a partir da obra original de 1789.

${ }^{21}$ Wilson Martins, História da inteligência brasileira, vol. I (1550-1794), São Paulo, Cultrix, 1977, p. 13 et seq.
} 
ainda na década de 1930, a leitura de perfil inquisitorial d'Il principe transmitida ao longo dos séculos, em primeiro lugar, pelos dicionários de português?

Observadas pelo viés paratextual, as mencionadas capas das duas traduções parte do que Gérard Genette define como paratexto — ${ }^{22}$ oferecem elementos importantes para responder às perguntas que fizemos. Elas ressaltam evidentes diferenças concernentes à vexata quaestio das normas ortográficas do português, como depreende-se da diversidade com que é transcrito o nome do secretário florentino: "Nicholas Machiavel" na edição brasileira e "Nicolau Maquiavel" na publicação lusitana. Esta última edição, "Com um artigo de Mussolini a servir de introdução", logo lembra o ocorrido na Itália havia pouco tempo: a publicação em 1928 da célebre edição Il principe con il preludio al Machiavelli di Benito Mussolini e il saggio di Francesco De Sanctis. ${ }^{23}$ Portanto, no contexto português de meados da década de 1930, a edição lusitana da Atlântida propõe uma leitura evidentemente conotada em termos político-ideológicos, de tal modo induzindo João Bettencourt da Câmara a defini-la, em 2005, como “A primeira Edição Portuguesa d'O príncipe ou o Maquiavel fascista de Francisco Morais". ${ }^{24}$

Anterior em dois anos à lusitana, a edição brasileira de Calvino Filho levou na capa a indicação de um prefácio de Mauricio de Medeiros, um intelectual que, além de sua atividade no campo médico psiquiátrico, distinguir-se-ia como escritor e polemista pelos cargos políticos exercidos nas presidências de Nereu Ramos e Juscelino Kubitschek de Oliveira. ${ }^{25}$ Em 1955, ele seria também membro da Academia Brasileira de Letras. ${ }^{26}$

\footnotetext{
${ }^{22}$ Gérard Genette, Soglie. I dintorni del testo, Tradução para o italiano de Maria Camilla Cederna, Torino, Einaudi, 1989

${ }^{23}$ Niccolò Macchiavelli, Il principe con il preludio al Machiavelli di Benito Mussolini e il saggio di Francesco De Sanctis, Milano, Società anonima Notari; Istituto Editoriale Italiano, 1928. O artigo "Preludio al 'Machiavelli”, de Mussolini, já aparecera em Gerarchia - Rivista politica, ano III, n. 4, abr. 1924. Cf. Edoardo Susmel; Duilio Susmel (orgs.), Opera omnnia, vol. 20, Firenze, La Fenice, 1956, p. 251-254.

${ }^{24}$ João Bettencourt da Câmara, "A primeira edição portuguesa d’O príncipe ou o Maquiavel fascista de Francisco Morais", Res-pública: revista lusófona de ciência política e relações internacionais, vol. 1, n. 1, 2005, p. 24 et seq. Disponível em: <http://recil.grupolusofona.pt/handle/10437/371>. Acesso em: 14 de julho de 2013. ${ }^{25}$ Ver Biblioteca da Presidência da República. Nereu Ramos. Ministérios. Disponível em: <http://www.biblioteca. presidencia.gov.br/ex-presidentes/nereu-ramos/ministerios> e Biblioteca da Presidência da República. Juscelino Kubitschek. Ministérios. Disponível em: <http://www.biblioteca.presidencia.gov.br/ex-presidentes/jk/ ministerios>. Acessos em: 13 de setembro de 2013.

${ }^{26}$ De acordo com o site da Academia Brasileira de Letras, Mauricio Campos de Medeiros foi: "Quarto ocupante da Cadeira 38, eleito em 28 de abril de 1955, na sucessão do Acadêmico Celso Vieira e recebido pelo Acadêmico Clementino Fraga em 9 de agosto de 1955. Mauricio de Medeiros nasceu na cidade do Rio de Janeiro a 14 de julho de 1885. Era filho de José Joaquim de Campos da Costa de Medeiros e de Maria Carolina Ribeiro de Medeiros. Faleceu Mauricio de Medeiros no Rio de Janeiro, a 23 de junho de 1966. Um de seus irmãos, Medeiros e Albuquerque, foi figura de relevante destaque nas letras brasileiras, tendo ocupado, na década de 1920, a presidência da Academia Brasileira de Letras. Médico, professor, escritor e político, estudou Mauricio de Medeiros no Colégio Pedro II e na Faculdade de Medicina do Rio de Janeiro, da qual viria a ser um dos professores catedráticos. Fez cursos de especialização médica na França, nos anos de 1906 e 1907. De regresso ao Brasil passou a colaborar em alguns periódicos do Rio de Janeiro e de São Paulo, entre os quais a 'Gazeta de Notícias' e o 'Correio Paulistano' - nos anos de 1908 e 1909. Retomada a atividade jornalística no Brasil em 1920, colaborou nos anos seguintes em 'A Gazeta' (São Paulo) e em 'A Noite', 'Correio da Manhã' e 'Diário Carioca' (Rio de janeiro). Envolvendo-se na política foi eleito deputado estadual no Estado do Rio de Janeiro em 1916 e deputado federal, em 1921. Voltou a ser eleito para a Câmara dos Deputados em 1927 e 1930. Em 1950 foi nomeado chefe da delegação brasileira ao I Congresso Mundial de Psiquiatria. Participou, também, dos congressos de Neuropatologia realizados em Roma e Londres, nos anos de 1952 e 1955, respectivamente. Exerceu o cargo de Ministro da Saúde nos governos de Nereu Ramos e de Juscelino K. de Oliveira". Quanto às suas obras, ver "Peço a palavra, 1924; Segredo conjugal, 1933; Idéias, homens e fatos, 1934; Folhas secas; Joaquim Nabuco, O casamento; O inconsciente diabólico; Rússia e Homens notáveis, 1964". Disponível em: <http://www. academia.org.br/abl/cgi/cgilua.exe/sys/start.htm?infoid=562\&sid=343>. Acesso em: 12 de setembro de 2013.
} 


\section{A denúncia de Medeiros}

Antes de irmos ao prefácio d'O principe editado por Calvino Filho, é necessário lembrar alguns dados pertinentes à atuação política de Mauricio de Medeiros naquele meio cultural carioca. Em 1932, ele publicara, com a mesma editora, Outras revoluções virão..., ensaio paradigmático dos conflitos políticos próprios ao Brasil no começo da década de 1930. De fato, ao reter o leitor no "Preambulo" - ou seja, segundo o léxico de Gérard Genette, no "limiar" do seu volume -, escreve Medeiros:

Quasi um anno e meio já passou sobre a surprehendente pacificação com que o Exercito Nacional, para evitar effusão de sangue, tomou a direcção do paiz de seus legitimos poderes, para entregal-a a um grupo de politicos, sobre cuja orientação doutrinaria nada se poude até agora perceber. Os actuaes governantes fallam, é certo, num programma revolucionario, num ideal revolucionario, numa acção revolucionaria a desenvolver. Mas tudo isso é tão inconsistente, que até agora nada de concreto e palpavel se exteriorizou, a não serem as perquisições sobre actos administrativos, de cuja responsabilidade não tem sido possivel exhimir alguns dos maioraes da propria Revolução inquiridora. ${ }^{27}$

Trata-se evidentemente da denúncia de uma grave situação política, na qual não haveria mais "legítimos poderes", gerada por uma "revolução" cujos "programmas" e "acções" seriam, segundo Medeiros, "inconsistentes". Sobre esses programas e ações, teceria amargas reflexões:

Apreciadas as cousas no terra a terra da vida administrativa, o que, imparcialmente, se verifica é que a falta de qualquer doutrina politica systematizada, que oriente o Governo Revolucionario, tem-n'o feito perder tempo, tactear, hesitar, com damno evidente para sua popularidade e ainda maior para a vida do paiz. Pouco a pouco os mesmos erros de seus antecessores legaes vão sendo repetidos. [...] E, enquanto isso, nenhum acto de projecção, de grandeza, de profundidade verdadeiramenre revolucionarias, foi praticado. Dir-se-ia que vivemos sob o mesmo culto da incompetencia, que caracteriza o regimen presidencial. ${ }^{28}$

Para defender sua tese de um Brasil vivendo "sob o mesmo culto da incompetencia" que caracterizara o anterior "regimen presidencial", Medeiros escolhe fazer uma exposição argumentativa, na qual uma série de perguntas correspondem a respostas com o fito de demonstrar como e por que os "revolucionarios" teriam falhado:

${ }^{27}$ Mauricio de Medeiros, Outras revoluções virão..., Rio de Janeiro, Calvino Filho, 1932, p. 8-9.

28/bidem, p. 8. 
Debalde busca-se nos actos a expressão dos objectivos reaes da Revolução. Combater oligarchias? Ellas ahi estão sendo substituidas pela parentela dos poderosos de hoje, empanada nos cartorios, nos logares redondos, nas sinecuras. Moralizar a administração? Não é em uma geração que se consegue tal objectivo, quando 40 annos de presidencialismo, do qual foram participes os politicos, que hoje governam o paiz, crearam o habito viciado de luxo de poder e de seu uso em proveito de classes e individuos privilegiados pelas graças do Governo. [...] Defender a autonomia federativa? E as intervenções nos Estados com a escandalosa política dos corrilhos dictando interventores bisonhos? E o Codigo dos Interventores? ${ }^{29}$

Ao avaliar os resultados, depois de "quasi um anno e meio", e os "objectivos reaes" dos "actos" feitos pela "Revolução" e seus vários protagonistas, Medeiros afirma:

Não é de atribuir má fé a esses chocantes dispauterios. O que um exame sereno das circunstancias mostra é que a força dos maus habitos não encontra, para resistir-lhe, a segurança de um Governo esteiado em uma doutrina politica systematica e coordenada. Estamos ha mais de um anno sendo governados sem Congresso. Parece que toda a furia revolucionaria se concentrou em extinguir o unico poder legitimamente representativo da opinião, em uma democracia: o Parlamento. ${ }^{30}$

Após denunciar como deu-se a "extinção" do "Parlamento", Medeiros continua levando sua análise às mais óbvias e inevitáveis consequências, salientando um assunto doravante crucial nos sucessivos capítulos de Outras revoluções virão... - a natureza do regime presidencialista no Brasil:

E' possivel que esse [o Parlamento], que ahi estava, não fosse senão uma imitação grotesca de um orgam representativo da soberania popular. Não tendo o regimen presidencial o remedio plastico e instantaneo da dissolução constitucional dos parlamentos medida admiravel que acaba de restituir á Inglaterra uma tranquillidade seriamente abalada - concebe-se que a opinião exacerbada faça dissolver, pela força, parlamentos e governos, que funccionem em divorcio do povo. Mas, se é em nome deste que remedio violento, de consequencias imprevisiveis, é applicado, por falta de melhor, o que a logica impõe é a immediata consulta ás urnas para indicação de seus novos mandatarios. ${ }^{31}$

Convencido de que o presidencialismo gerara, durante 40 anos, grandes males e que os políticos revolucionários continuavam na mesma linha, Medeiros afirma:

\footnotetext{
${ }^{29}$ Mauricio de Medeiros, Outras revoluções virão..., Rio de Janeiro, Calvino Filho, 1932, p. 8-9.

$30 /$ bidem, p. 10.

${ }^{31}$ lbidem.
} 
E' impossivel, até á hora presente, prever em que sentido se orientará o paiz, quando um dia, lhe for dado dizer como quer ser governado. A maior parte dos habilissimos politicos, que orientam em seu proveito o descontentamento popular, é francamente adepta do regimen presidencial. [...] Os revolucionarios vencedores ficam em superficialidades, quando se lhes pede que apontem taes erros. Dir-se-ia que temem ir ao fundo da ferida. Si forem, verão que o mal unico, o mal essencial, o mal a curar no Brasil é esse proprio regimen presidencial, que a surpreza de 1889 conseguio implantar na Constituição de 24 de fevereiro. ${ }^{32}$

A conclusão a que chega o autor é expressa nos seguintes termos:

E' a isso que se propõe este livro, sem visar os homens senãonas ligações deseus actos com a these que se pretende defender. Sio Brasil sahirdesta Revolução, mantendo o regimen de 24 de fevereiro, esse movimento, que tão profundos abalos está causando ao paiz, terá fracassado no seu objectivo, inconsciente, mas sensivel na alma nacional. E, então, não tenham a menor duvida: outras revoluções virão... ${ }^{33}$

Medeiros retorna à questão da perigosa continuidade presidencialismo/ revolução em vários pontos de seu ensaio, sem poupar referências explícitas aos nomes que julga serem responsáveis por um processo gerador de "tão profundos abalos" para o país, como se lê, por exemplo, no capítulo IX, "Os factores reaes da revolução de 1930":

A Revolução de 1930 fez-se sem outro programma, além da simples conquista do Poder. E' facto sabido que, ao chegar ao Rio de Janeiro com o caminho desobstruido de embaraços béllicos devido á curiosa "pacificação" dos generaes da guarnição do Rio, o sr. Getulio Vargas se considerava presidente eleito da Republica para o quatriennio de 1930-34: - eleito pelo povo, esbulhado pelo Congresso e empossado pela Nação em armas! ${ }^{34}$

Nas páginas finais do seu ensaio, Medeiros descreve quais sentimentos e intuitos levaram-no a escrevê-lo:

Este meu livro, escripto sem nenhuma especie de contensão mental, contem o de que meu pensamento vem cheio desde que comecei a opinar de publico. Mais de vinte annos de jornalismo, de vida intellectual no magisterio, nas tribunas de conferencia, nas do Parlamento - nunca me deixaram comprehender de outra forma as cousas brazileiras. As circumstancias me collocaram entre os que perderam posição politica por effeito da Revolução, cujas causas eu proprio busco, não nos homens que eventualmente lhe tomaram a direcção, mas na sequencia logica dos acontecimentos. [...] Não contem, pois, estelivro, amarguras de saudosista. Nem tampouco ancia de adhesão na busca commum de formulas de reforma. São paginas de quem lamenta a falta de reflexão historica, e de quem vê tão claro aquilo que só a ignorancia procura fazer confusão. ${ }^{35}$

${ }^{32}$ Mauricio de Medeiros, Outras revoluções virão..., Rio de Janeiro, Calvino Filho, 1932, p. 13-14.

33/bidem, p. 15.

34/bidem, p. 90-91.

35/bidem, p. 240-241. 


\section{O prefaciador}

Como já fizera no "Preambulo" de Outras revoluções virão..., Medeiros, ao escrever no ano seguinte seu prefácio a'O principe publicado pela Calvino Filho, revelaria com clareza seus intuitos (Figura 2). Mas seu engajamento político manifesta-se dessa vez de outra forma. Ele escolhe uma abordagem linguística - mais exatamente, semântico-lexical - para introduzir o leitor à compreensão de uma obra que poderia ajudar na "reflexão historica",

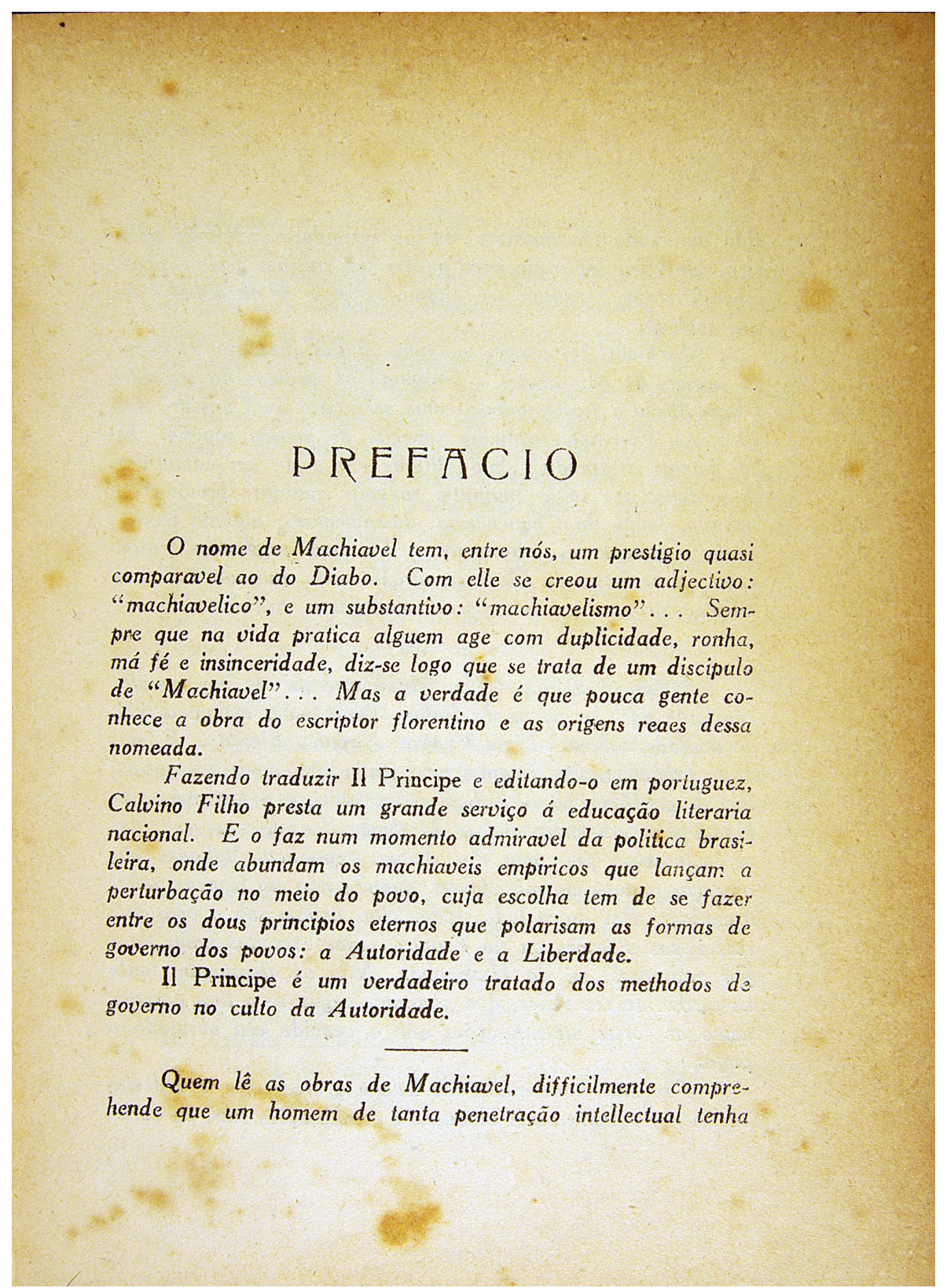


referente, segundo sua perspectiva, à difícil atualidade política brasileira do momento:

Onome de Machiavel tem, entre nós, um prestigio quasi comparavel ao do Diabo. Com elle se creou um adjectivo: "machiavelico", e um substantivo: "machiavelismo"... Sempre que na vida pratica alguem age com duplicidade, ronha, má fé e insinceridade, diz-se logo que se trata de um discipulo de "Machiavel"... Mas a verdade é que pouca gente conhece a obra do escriptor florentino e as origens reaes dessa nomeada. ${ }^{36}$

Se considerarmos a "posição" escolhida pelo prefaciador para sua intervenção - parafraseando as palavras de Genette, que não é "neutra" —, ${ }^{37}$ ele esclarece o ponto de partida de suas reflexões com argumentos especificamente semântico-linguísticos, propostos como se fossem óbvios a qualquer brasileiro. Porém, observadas com mais atenção, essas ideias levantam algumas questões. Segundo sua consciência linguística e cultural, o prefaciador considera óbvia para o "nome de Machiavel" uma acepção conotativa pejorativa, semanticamente ainda pior que as geralmente registradas pelos dicionários de português. ${ }^{38}$ Segundo Medeiros, dizer "Machiavel" "entre nós" nos primeiros anos da década de 1930 seria quase equivalente a dizer "Diabo". Ou seja, na consciência linguístico-cultural comum brasileira, a palavra "Machiavel" teria significados típicos de outros âmbitos linguístico-culturais, por exemplo, de matriz anglo-saxônica. Entre eles, desde o Seiscentos, afirmara-se um maquiavelismo específico que levaria à fixação no inglês - além da família de palavras derivadas do nome comum "Machiavel" - de certas locuções, por exemplo, Much Evil, Mitchell Wylie, Match a Villain, Hatch Evil, cujos significados equivaleriam, para todas, a "Satanás" ("Satan", "Devil"). ${ }^{39}$

Ora, procurando "ajudar" seus leitores na compreensão da obra de um "Machiavel” quase "Diabo", Medeiros acrescenta outros detalhes de ordem semântica: "Sempre que na vida pratica alguem age com duplicidade, ronha, má fé e insinceridade diz-se logo que se trata de um discipulo de 'Machiavel..... Detalhes que, ao contrário do salientado nas duas primeiras orações, lembram facilmente algumas definições de dicionários monolíngues, no caso, de português. Nesses

\footnotetext{
${ }^{36}$ Mauricio de Medeiros, "Prefacio", In: Nicholas Machiavel, O principe, Tradução de Elias Davidovich, Rio de Janeiro, Calvino Filho, 1933, p. V.

${ }^{37}$ Gérard Genette, Soglie. I dintorni del testo, Tradução para o italiano de Maria Camilla Cederna, Torino, Einaudi, 1989, p. 168.

${ }^{38}$ Sandra Bagno, "Il principe di Machiavelli nelle lessicografie latinoamericane: il Brasile caso emblematico? Dall'eredità culturale del colonizzatore all'autonomia lessicografica specchio di un'identità nazionale", In: María Begoña Arbulu Barturen; Sandra Bagno, La recepción de Maquiavel y Beccaria en ámbito ibero-americano, Padova, Unipress, 2006, p. 192 et seq. Sandra Bagno, “'Maquiavélico' versus 'maquiaveliano' na língua e nos dicionários monolíngues brasileiros", Cadernos de tradução, vol. 2, n. 22, Florianópolis, 2008, p. 130 et seq Disponivel em: <http://www.periodicos.ufsc.br/index.php/traducao/article/view/2175-7968.2008v2n22p129>. Acesso em: 29 de setembro de 2013.

${ }^{39}$ Alessandra Petrina, "Machiavelli in Inghilterra e Scozia: il primo secolo del Principe in lingua inglese"; Michele Ciliberto, "Machiavelli e II principe nell'Inghilterra tra il XVI e il XVII secolo", In: Alessandro Campi (org.), II principe di Niccolò Machiavelli e il suo tempo 1513-2013, Roma, Istituto della Enciclopedia Italiana fondata da Giovanni Treccani, 2013, p. 186-194; 235-247.
} 
dicionários, contudo - como vimos —, os lexicógrafos não chegaram ao ponto de evocar o "Diabo" para definir o nome comum "Machiavel".40

É difícil compreender hoje se, com esse incipit, o prefaciador sinalizava, ao escrever "entre nós", uma acepção em sentido "diabólico" verdadeiramente compartilhada pela consciência linguística e cultural comum brasileira da época, mas não registrada pelos lexicógrafos. Entretanto, partindo de premissas semântico-linguísticas, Medeiros acaba concluindo o primeiro parágrafo de seu prefácio assinalando: "Mas a verdade é que pouca gente conhece a obra do escriptor florentino e as origens reaes dessa nomeada". ${ }^{41}$ Ou seja, com uma segunda "verdade", ligada a questões de natureza linguística.

Como Medeiros confere a suas afirmações uma função axiomática, alguns elementos importantes destacam-se do primeiro parágrafo de seu prefácio. O fato d'Il principe ser conhecido na década de 1930, segundo ele, por um público limitado ("pouca gente"), dever-se-ia à circulação no Brasil da obra maquiaveliana traduzida para outras línguas, com as previsíveis implicações de

\section{Much Evil, Mitchell Wylie, Match a Villain, Hatch Evil, cujos significados equivaleriam, para todas, a "Satanás" ("Satan", "Devil")}

natureza tradutória e/ou paratextual - e, portanto, interpretativas daí decorrentes. E, se considerarmos, por exemplo, que na biblioteca de Machado de Assis constava, segundo o recenseamento feito em 1960 por Jean-Michel Massa, uma edição francesa de "MACHIAVEL. Essai sur les oeuvres et la doctrine de Machiavel, avec la traduction littérale du Prince et de quelques fragments historiques et littéraires..." ${ }^{42}$ pode-se, então, formular a hipótese de aquela "pouca gente" referida por Medeiros ter desfrutado a possibilidade de ler Il principe ao menos em francês. Um ambiente cultural, porém, que levanta outras questões, tendo em vista a história específica do maquiavelismo delineada ao longo dos séculos e as diferentes leituras da obra maquiaveliana

\footnotetext{
${ }^{40}$ Sandra Bagno, "Il principe di Machiavelli nelle lessicografie latinoamericane: il Brasile caso emblematico? Dall'eredità culturale del colonizzatore all'autonomia lessicografica specchio di un'ídentità nazionale", In: María Begoña Arbulu Barturen; Sandra Bagno, La recepción de Maquiavel y Beccaria en ámbito ibero-americano, Padova, Unipress, 2006, p. 192 et seq. Sandra Bagno, 'Maquiavélico' versus 'maquiaveliano' na língua e nos dicionários monolíngues brasileiros", Cadernos de tradução, vol. 2, n. 22, Florianópolis, 2008, p. 130 et seq. Disponivel em: <http://www.periodicos.ufsc.br/index.php/traducao/article/view/2175-7968.2008v2n22p129>. Acesso em: 29 de setembro de 2013.

${ }^{4}$ Mauricio de Medeiros, "Prefacio", In: Nicholas Machiavel, O principe, Tradução de Elias Davidovich, Rio de Janeiro, Calvino Filho, 1933, p. V.

42Jean-Michel Massa, "110. MACHIAVEL. Essai sur les oeuvres et la doctrine de Machiavel, avec la traduction littérale du Prince et de quelques fragments historiques et littéraires par Paul Deltuf. Paris, C. Reinwald, 1867. [Garnier]", In: _. La bibliothèque de Machado de Assis. Separata da Revista do Livro, Rio de Janeiro, n. 2122, Mar-Jun. 1961, p. 208.
} 
feitas por ilustrados e românticos, ${ }^{43}$ leituras aludidas pelo próprio Medeiros no seu prefácio. Não obstante, uma questão com tantas implicações como a das fontes não é mencionada em outra parte do paratexto da edição de Calvino Filho, tampouco pelo próprio prefaciador ao apresentar ao público brasileiro a tradução de Elias Davidovich. Mas, então, partindo do pressuposto de que "entre nós" - ou seja, na identidade linguística e cultural brasileira - "Machiavel" significaria quase o "Diabo", a quais leituras d'O principe se referia Medeiros ao escrever seu prefácio, misturando um plano especificamente linguístico ao conteudístico? Em outras palavras, ele alude a um "Machiavel" quase "Diabo" influenciado por qual tipologia de maquiavelismo e, após ter lido Il principe, por que meio linguístico?

\section{O principe em português}

Ora, mesmo reconhecendo que o silêncio de Medeiros sobre o prototexto possa ser facilmente relacionado a certos hábitos editoriais comuns à época, ele revela-se bastante significativo se vinculado a outro dado, evidente já a partir do segundo parágrafo do prefácio:

Fazendo traduzir Il Principe e editando-o em portuguez, Calvino Filho presta um grande serviço á educação literaria nacional. E o faz num momento admiravel da politica brasileira, onde abundam os machiaveis empiricos que lançam a perturbação no meio do povo, cuja escolha tem de se fazer entre os dous principios eternos que polarisam as formas de governo dos povos: a Autoridade e a Liberdade. Il Principe é um verdadeiro tratado dos methodos de governo no culto da Autoridade. ${ }^{44}$

O prefaciador expressa-se com clareza e seu texto revela-se um instrumento legitimador do seu posicionamento político. Seu alvo não é, após séculos de censura, apresentar uma obra como $O$ príncipe segundo uma linha isenta de preconceitos. Ao contrário, Medeiros afirma ser exatamente naquele contexto histórico que Il principe, finalmente em português, permitiria a um público maior reconhecer "os machiaveis empiricos" atuando num "momento admiravel da politica brasileira", quando já se afirmara, evidentemente, a autoridade de Getúlio Vargas. Nome, porém - diferentemente do que vimos nas páginas de Outras revoluções virão... - nunca expressamente citado. O "Prefacio" a'O principe da edição carioca revela-se, assim, uma clara denúncia contra aqueles que Medeiros acredita serem os inimigos da "Liberdade". Il principe, citado em italiano e definido simplesmente como "um verdadeiro tratado dos methodos de governo no culto da Autoridade",

\footnotetext{
${ }^{43}$ Bianchi Bensimon, "Il principe di Machiavelli nella Francia del XVI secolo"; Jacob Soll, "La traduzione del Principe di Amelot (1683)"; Maurizio Tarantino, "/l principe nella tradizione politico-letteraria europea dell'Ottocento", In: Alessandro Campi (org.), Il principe di Niccolò Machiavelli e il suo tempo 1513-2013, Roma, Istituto della Enciclopedia Italiana fondata da Giovanni Treccani, 2013, p. 177-183; 184-185; 259-268.

${ }^{44}$ Mauricio de Medeiros, "Prefacio", In: Nicholas Machiavel, O principe, Tradução de Elias Davidovich, Rio de Janeiro, Calvino Filho, 1933, p. V.
} 
é primeiramente invocado segundo a lógica da militância política e, depois, de modo puramente instrumental. Ou seja, Il principe é definido como o "tratado" - arquétipo negativo por definição - graças ao qual é possível desmascarar o que em 1933 já demonstrara ser um regime autoritário, cujas responsabilidades eram de uns específicos "machiaveis", para Medeiros, facilmente reconhecíveis também pelo "povo" brasileiro, mesmo adotando no seu prefácio uma linha expressiva apenas alusiva.

Mas o prefaciador evidencia outro elemento concernente ao clima cultural e à maneira com que, no começo da década de 1930, se travava a luta política na capital. Ao permitir aos brasileiros lerem Il principe em português, a editora Calvino Filho prestaria "um grande serviço á educação nacional": afirmação especialmente significativa se levarmos em conta a linha editorial e o papel político desenvolvidos por Calvino Filho durante o "varguismo". A propósito, escreve Laurence Hallewell:

\begin{abstract}
A Editorial Calvino já existia pelo menos desde 1932 com o nome de Calvino Filho. Em 1943, publicou algumas séries, como a "Coleção de Estudos Sociais" (em que foi publicada, por exemplo, Lenine, de D. S. Mirski), "A verdade sobre a Rússia" (com, por exemplo, O Cristianismo e a Nova Ordem Social, de Hewlett Johnson, o Deão "vermelho" de Canterbury, Missão em Moscou, do antigo embaixador norte-americano Joseph Davies, Stalin de Emil Ludwig, Dez Dias que Abalaram o Mundo, de John Reed) e "Luta pela Liberdade" (com obras como A China Luta pela Liberdade de Ana Louise Strong). Em 1944, a Calvino acrescentou a seu catálogo o Anti-Dühring de Engels e, em 1945, URSS: Uma Nova Civilização, de Sydney e Beatrice Webb, época em que se revelou ser o órgão da seção carioca do Partido Comunista. ${ }^{45}$
\end{abstract}

Partindo, portanto, de um posicionamento oposto a quem estava no poder, Medeiros é, então, um dos intelectuais ativos numa editora engajada politicamente, cujo alvo seria a "educação nacional". Ele é um dos intelectuais que contribuíam para a difusão, nomeadamente mediante traduções, de obras que, caso contrário, não seriam facilmente atingíveis por grande parte da sociedade brasileira. A escolha de publicar Il principe em versão integral fundamentava-se na convicção de que somente assim aquela obra poderia demonstrar sua natureza de "tratado dos methodos de governo no culto da Autoridade".

\title{
Vida modesta e de insucessos
}

Observemos agora as argumentações escolhidas por Medeiros para fazer com que também seus leitores interpretem - em sentido "diabólico" - Il principe, proibido por tanto tempo, revelando-se um ótimo instrumento

${ }^{45}$ Laurence Hallewell, O livro no Brasil: sua história, São Paulo, Edusp, 2005, p. 508. 
para os brasileiros reconhecerem os responsáveis por um processo político naquele momento já nitidamente autoritário. Aceitando implicitamente lógicas inquisitoriais típicas do Quinhentos, Medeiros acaba por confirmar (inconscientemente?) a linha interpretativa de Rafael Bluteau que, no Vocabulario portuguez \& latino, definiu o verbete "Machiabelista" nos seguintes termos:

\begin{abstract}
Machiabelista, ou Machiavelista. He o nome que se deo aos sequazes da doutrina de Nicolao Machiavello, Florentino, Secretario da Republica de Florença, nos annos de 1400. \& Autor de hũs livros Politicos, cheyos de perniciosos dogmas. Foy Machiavello accusado de haver sido complice em duas conjurações contra a casa de Medicis, cahio depois em miseria, \& com opinião de Atheo, ou Deista, sem religião alguma, no anno de 1528 ou 1529 morreo de hũa purga, que elle tomou fóra de tempo. ${ }^{46}$
\end{abstract}

Pois bem, ao reforçar no século XX essa linha depreciativa de matriz inquisitorial, Medeiros acrescenta algumas informações com o objetivo de induzir seus leitores a menosprezarem a figura e a obra do "Diabo" Maquiavel. Passa, assim, a arrolar — de modo bastante impreciso - uma série de dados biográficos e historiográficos, que o leitor da primeira tradução d' $O$ príncipe não poderia deixar de depreender. Mesmo tendo sido Maquiavel um "homem" de grande "penetração intellectual", sua vida seria, substancialmente, de "verdadeiros insucessos":

Quem lê as obras de Machiavel, difficilmente comprehende que um homem de tanta penetração intellectual tenha tido uma vida tão modesta, de tão secundaria actuação politica, tão cheia de insuccessos mesmo nas missões diplomaticas, que deveriam constituir um campo propicio ás faculdades de seu espirito. Machiavel foi sempre um funccionario obediente e attento ás ordens de seus chefes. Dirigindo os serviços da segunda Chancellaria e funccionando como secretario do Conselho dos Dez, em Florença, nenhuma funcção de mando superior lhe foi jamais attribuida. Sua attitude era a de um cumpridor de ordens, que só se permittia suggerir qualquer providencia quando, longe da Chancellaria, desempenhava alguma missão junto a potentados estrangeiros. De suas suggestões, entretanto, a Senhoria de Florença raramente se utilisava. E suas missões foram, em sua maioria, verdadeiros insucessos. ${ }^{47}$

\footnotetext{
${ }^{46}$ Sandra Bagno, "Il principe di Machiavelli nelle lessicografie latinoamericane: il Brasile caso emblematico? Dall'eredità culturale del colonizzatore all'autonomia lessicografica specchio di un'identità nazionale", In: María Begoña Arbulu Barturen; Sandra Bagno, La recepción de Maquiavel y Beccaria en ámbito ibero-americano, Padova, Unipress, 2006, p. 192 et seq.

${ }^{47}$ Mauricio de Medeiros, "Prefacio", In: Nicholas Machiavel, O principe, Tradução de Elias Davidovich, Rio de Janeiro, Calvino Filho, 1933, p. V-VI.
} 
Logo em seguida, Medeiros começa a descrever a realidade histórica de atuação do secretário florentino, partindo do pressuposto de que a "attitude" maquiaveliana era a de um simples "cumpridor de ordens". A fragmentação política da península permitia que potências estrangeiras como "França", "Hespanha" e o "Imperador" (do Sacro Império) visassem ampliar seus respectivos territórios e esferas de influências, em detrimento dos pequenos estados italianos impossibilitados de se defenderem ante esses fortes exércitos. À cobiça de conquistas territoriais dessas monarquias correspondia uma "intranquillidade interna" dos italianos, acostumados a políticas feitas de lutas ferozes entre "facções partidarias" e "grupos de familias". A fraqueza dessas "provincias", entre si "tão distantes pelo sentimento", e de "republiquetas" ou "principados" dominados por diversas intrigas seria emblemática da imoralidade de cada um, reduzindo a política a "envenenamentos" e "assassinatos traiçoeiros", ditados sobretudo pelas ambições pessoais. Ninguém seria imune, salienta Medeiros, a esse modo de interpretar a política: "Até a Igreja Romana é um centro de agitação politica e de ambição terrena". Passando depois a descrever a situação de Florença, pela qual trabalhava Maquiavel, Medeiros lembra que a cidade procurava salvar sua identidade de "republica democratica" rica, graças a sua florescente atividade comercial. Por isso mesmo, ela tornara-se alvo das cobiças de "vizinhos mais fortes". Quanto a Maquiavel, seu trabalho em favor de Florença como "secretario do 'Conselho dos Dez da Liberdade e da Paz"' e "chefe da segunda chancellaria" seria raramente exitoso. Como assinala Medeiros, ele nunca teria obtido a honra de atuar como "embaixador". 48

\section{Habilidades políticas}

Nesse contexto tão complexo, Maquiavel tornar-se-ia primeiro vítima, depois, teórico de um modo específico de fazer política, do qual seria paradigmática conforme Medeiros - a "missão" do secretário florentino junto à "condessa Catarina Sforza". Sobre essa missão, afirma Medeiros:

Nas obras biographicas sobre Machiavel encontram-se todos esses detalhes das negociações entaboladas por Machiavel e que terminaram num imprevisto fracasso, pois, tendo concluido o assumpto numa noite, na manhã seguinte, na hora de assignar, a Condessa formulara uma nova exigencia. Deante da surpresa de Machiavel a Condessa se justificou dizendo que "as cousas se comprehendem tanto melhor, quanto mais são discutidas". ${ }^{49}$

\footnotetext{
${ }^{48}$ Mauricio de Medeiros, "Prefacio", In: Nicholas Machiavel, O principe, Tradução de Elias Davidovich, Rio de Janeiro, Calvino Filho, 1933, p. VI-VIII.

49/bidem, p. VIII-IX.
} 
Como afirma Medeiros, uma "habilidade", posteriormente definida "machiavélica", inspirava o comportamento desleal da "Condessa". "Habilidade" sofrida por Maquiavel, sendo algo exposto posteriormente pelo secretário florentino n'O príncipe..$^{50}$ Nesse tratado, Maquiavel sistematizaria ideias, fruto de um aprendizado conseguido também no "convivio de cortes estrangeiras em cujas intrigas se educava" e onde teria entrado em contato com políticos como Cesar Bórgia, que exerceria uma influência deveras "seductora" sobre Maquiavel, nele acreditando reconhecer o seu "príncipe" ideal:

Cesar Borjia era então o chefe mais temido, apesar da mocidade de seus 26 annos. Machiavel sente logo a influencia seductora do caracter nitido do principe. Mais tarde volta a negociar sósinho com elle e passa perto de 4 mezes no seu convivio. E tudo faz crêr que fossem os ensinamentos recebidos nesse convivio que lhe suggerissem mais tarde, no ostracismo, muitos dos paragraphos de seu livro Il Principe. ${ }^{51}$

Quando Maquiavel encontrou-se sem apoio político e empobrecido, só lhe restava dedicar-se aos estudos. Nessa predisposição, salienta o psiquiatra Medeiros, o pensador italiano escreveria suas obras:

A historia de Machiavel não faria jamais suppor que sua obra merecesse da posteridade a consagração que teve. Quando Florença, combatida por varios inimigos, voltou ao dominio dos Medici, a perseguição que se move contra Machiavel não o poupa nem da prisão, nem das torturas. E' um episodio deprimente para o caracter de Machiavel, que se humilha vergonhosamente perante os inimigos. Sem meios para viver na cidade, retira-se elle, com sua familia, para uma pequena propriedade que possuia nos arredores, em S. Cassio. E' ahi que escreve O Principe, os Discursos sobre as Decades de Tito-Livio, a Arte de Guerra, e varias peças de theatro. ${ }^{52}$

Mas o prefaciador não se limita a expressar sua admiração pela "consagração" póstera tributada a Maquiavel por seu O príncipe. Ele chega a "condicionar" seu leitor afirmando:

Seu livro O Principe, ora traduzido, tinha um objectivo mesquinho. Machiavel se sentia sem recursos, no seu ostracismo. Queria um emprego. Escreveu $O$ Principe para ser lido pelos Medici, para que estes vissem sua capacidade nos negocios publicos e a aproveitassem dando-lhe um emprego na administração. Tendo morrido aquelle a quem era feita a dedicatoria, elle não teve duvidas: dedicou o livro ao outro. No fundo, tendo em vista agradar um soberano, Machiavel sustenta no Principe os methodos de se manter um governo pela autoridade. ${ }^{53}$

\footnotetext{
${ }^{50}$ Mauricio de Medeiros, "Prefacio", In: Nicholas Machiavel, O principe, Tradução de Elias Davidovich, Rio de Janeiro, Calvino Filho, 1933, p. VIII.

51/bidem, p. IX

52/bidem, p. IX-X.

53/bidem, p. X.
} 
Tendo como verdadeiro objetivo "agradar um soberano", o secretário florentino, citando "exemplos historicos numerosos" e "casos que apreciou", acabaria tirando "regras geraes que constituem, no seu conjuncto, um manual de governo pela força, pela violencia e pela astucia". ${ }^{54}$ Portanto, conclui Medeiros, com toda razão "Poder-se-á dahi concluir que Machiavel tenha creado aquillo que hoje se chama 'machiavelismo"."55

Mas, mesmo sendo seu detrator, Medeiros reconhece - embora apenas indique brevemente a questão — que, para Maquiavel, a "Liberdade" não era menos importante:

Não ha a menor duvida de que sua obra merece ser lida por quem queira ter uma visão de politica, ao tempo do Renascimento italiano. Seus conceitos tanto na technica do exercicio da Autoridade, quanto no da Liberdade, guardam, por vezes, um frescor eterno, porque são syntheses de estados de alma humana, cuja evolução não tem sido grande..$^{56}$

\section{Il principe, finalmente em português, permitiria a um público maior reconhecer "os machiaveis empiricos" quando já se afirmara, evidentemente, a autoridade de Getúlio Vargas}

À concessão feita a um Maquiavel atento "tanto na technica do exercicio da Autoridade, quanto no da Liberdade", Medeiros logo contrapõe seu ceticismo sobre a "sinceridade" do secretário florentino:

Mas essa propria felicidade em exprimir tanto o que serve á Autoridade, no "Principe", como o que serve á Liberdade, nos "Discursos sobre as Decades de Tito Livio", é que me faz sceptico quanto á sinceridade do Autor, num como noutro dos rumos de seus trabalhos. ${ }^{57}$

No começo da década de 1930, a primeira tradução para o português d'O príncipe acaba sendo proposta ao "povo" brasileiro como instrumento de engajamento político e luta contra a difícil situação contingente. Mas, com efeito, ela confirmava a leitura inquisitorial transmitida ao longo dos séculos, inclusive pelos dicionários monolíngues, sobre Maquiavel e sua obra. Mesmo inspirado nos ideais libertários - outrora tendo animado também a Maquiavel, como o próprio Medeiros reconhece -, o prefaciador acaba mantendo-se nos rastros dos

\footnotetext{
${ }^{54}$ Mauricio de Medeiros, "Prefacio", In: Nicholas Machiavel, O principe, Tradução de Elias Davidovich, Rio de Janeiro, Calvino Filho, 1933, p. X.

${ }^{55}$ /bidem, p. XI.

${ }^{56 / b i d e m, ~ p . ~ X I-X I I . ~}$

${ }^{57}$ Ibidem, p. XII.
} 
detratores e inquisidores, à maneira de Jerónimo Osório. Isso demostrava que, ainda na primeira metade do Novecentos, Il principe não acabara de impor, segundo as palavras de Rodolfo De Mattei, sua "imperiosa suggestione".58 E talvez Medeiros tenha sido sensível a esse fascínio ao aproximar-se do fim de seu "Prefacio" e afirmar:

De qualquer forma, porém, não se pode pensar em uma cultura politica, sem conhecer as duas principaes obras de Machiavel. Calvino Filho fez bem em traduzir O Principe. Elle vem mostrar a muita gente como a humanidade pouco mudou nestes quatro seculos. Machiavel nasceu em 3 de Maio de 1469 e escreveu o Principe pouco depois de $1500 . .$. Por essa época, descobria-se o Brasil e começava o lento trabalho de sua colonisação. Quatrocentos e trinta trez annos se passaram e a obra de Machiavel, lida em nossa lingua, na traducção, que Calvino Filho aqui lhe dá, parece um delicioso conjuncto de epigrammas de uma actualidade palpitante... [...] Positivamente o Brasil está na hora de ler Machiavel!... ${ }^{59}$

É difícil entender, retornando a Benedetto Croce, se, quando o filosofo italiano falava no "descontentamento" produzido pelos "muitos livros, italianos e estrangeiros sobre Maquiavel", ele poderia aludir também à primeira tradução d'O príncipe de Calvino Filho e a seu "Prefacio". Mas, como vimos, uma daquelas três interpretações, segundo Croce erradas, encontra-se também nesse prefácio de Medeiros. Assim, sintetizamos a sua interpretação parafraseando Croce. Por essa visão, Maquiavel teria colocado "por escrito aqueles que seriam os costumes do seu tempo".

Com efeito, a primeira tradução integral d'O principe para o português, que deveria ter sido, teoricamente, a primeira peça de uma possível história do maquiavelismo brasileiro, ao chegar com quatro séculos de atraso, acabou caindo num terreno predisposto ab imis, ou seja, vacinado desde o Quinhentos "contra" Maquiavel, como pessoa e/ou autor.

Apenas estudos filologicamente atentos aos diferentes aspectos do clima político e cultural do momento permitem-nos entender quais teriam sido as fontes de Medeiros ao prefaciar seu $O$ principe, pela editora Calvino Filho, e compreender quais eram os destinatários, além do "Machiavel" / "Diabo" Getúlio Vargas, ao realizar seu ataque político à "Autoridade" brasileira no momento. Essa investida, porém, obriga-nos a estender a pesquisa para além das fronteiras nacionais. Conforme a lógica alusiva adotada por Medeiros, seu prefácio pode com toda razão ser interpretado igualmente como uma resposta de parte da inteligência

${ }^{58}$ Rodolfo De Mattei, Dal premachiavellismo allantimachiavellismo, Firenze, Sansoni, 1969, p. VII. "Forte fascínio" (tradução da autora).

${ }^{59}$ Mauricio de Medeiros, "Prefacio", In: Nicholas Machiavel, O principe, Tradução de Elias Davidovich, Rio de Janeiro, Calvino Filho, 1933, p. XII. 
brasileira, preocupada em termos políticos em relação ao autoritarismo de Vargas, e talvez como uma reação àquele Principe col preludio al Machiavelli..., publicado por um Mussolini que usara, como se sabe, a obraprima maquiaveliana também de forma instrumental. ${ }^{60}$ Trata-se de uma resposta compreensível e preocupada, mas à custa, novamente, de um entendimento mais adequado sobre a importância de Maquiavel e de sua obra na história da cultura ocidental.

60Sobre o uso instrumental feito por Mussolini de Maquiavel e sua obra prima, ver Laura Mitarotondo, "I principe fra il 'Preludio' di Mussolini e le letture del Ventennio", In: Luigi Marco Bassani; Corrado Vivanti (orgs.), Machiavelli nella storiografia e nel pensiero politico del XX secolo, Milano, Giuffrè, 2006, p. 59 et seq. 